\title{
Presence of Schistosomiasis in Genital Biopsies from patients at the University Teaching Hospital in Lusaka, Zambia
}

\author{
*Mable M. Mutengo ${ }^{1,2,4}$, Victor Mudenda ${ }^{1}$, James C. Mwansa ${ }^{1,2}$, Kennedy Kaonga ${ }^{1}$, Sandie Sianongo $^{1,2}$, \\ Helen I. Wamulume ${ }^{1}$ and Cecilia J. Shinondo ${ }^{3 / 4}$ \\ ${ }^{I}$ Department of Pathology and Microbiology, University Teaching Hospital, Lusaka, Zambia \\ ${ }^{2}$ Zambia Bilharzia control program, Lusaka, Zambia \\ ${ }^{3}$ Department of Biomedical Sciences, University of Zambia, Lusaka, Zambia \\ ${ }^{4}$ School of Medicine and University Teaching Hospital-Malaria Research Unit
}

\begin{abstract}
Background: Ectopic localizations of the adult Schistosomes and ova in the genital tract of individuals living in schistosoma endemic areas are common. The infection can affect both male and female reproductive organs, and although it is predominant in adult women, case reports in girls younger than 15 years of age have been documented.
\end{abstract}

Objective: The objective of this review was to determine and document the presence of genital schistosomiasis from biopsy specimens.

Methods: Patients' laboratory records at the University Teaching Hospital histopathology laboratory for the period 2001 to 2007 were retrieved and reviewed for reports on the presence of schistosomiasis. Data were analysed by age, sex and biopsy site.

Results: Thirty eight (65.5\%) of the 58 specimens with schistosomiasis were from the genital organs. Female genital tract schistosomiasis was more prevalent $(84.2 \%)$ than male genital schistosomiasis $(15.8 \%), \mathrm{p}<0.001$. Schistosomiasis was high in biopsy specimens collected from the cervix

\footnotetext{
*Corresponding Author:

Mable M Mutengo,

Dept of Pathology and Microbiology,

University Teaching Hospital,

P/Bag RW1X, Lusaka, Zambia.

Email:mmutengo@yahoo.com
}

(34.2\%), followed by those from the vulva (13.2\%). In male patients, the distribution of the infection was $2(5.3 \%)$ each in the prostate, spermatic cord and testicular tissues. Malignancy was clinically suspected in $74 \%$ of genital schistosomiasis patients but histologically only 3 cases of malignancy were detected alongside the schistosoma infections.

Conclusion: Our results indicate that genital schistosomiasis is common in Zambia. Uterine cervical schistosomiasis was the most prevalent form of female genital schistosomiasis and mostly affected middle aged women.

\section{INTRODUCTION}

Human schistosomiasis affects approximately 200 million people worldwide and the majority of these infections (165 million) occur in Sub-Saharan Africa. About 112 million of the infections in this region are due to Schistosoma haematobium and 54 million are as a result of Schistosoma mansoni. In Zambia, schistosomiasis affects about 2 million people indicating that close to $17 \%$ of the total national population have the infection.

The normal localization of human schistosomes are the mesenteric veins for $S$. mansoni and $S$. japonicum or pelvic veins for $\mathrm{S}$. haematobium $^{3,4}$. However, ectopic localizations of the adult Schistosoma worms and subsequent deposition of ova in adjacent tissues such as the genital tract has been reported ${ }^{4,5}$. It is estimated that approximately $30 \%$ to $75 \%$ of women with 
S.haematobium infection may develop genital lesions attributable to this infection. In Zambia, genital schistosomiasis was reported as far back as the 1980 s by Atilli and colleagues ${ }^{7}$.

Though genital schistosomiasis predominantly affects females, the presence of Schistosoma ova in male genital organs such as the testis and spermatic cords has been reported ${ }^{5,8}$. The presence of schistosoma ova in female and male reproductive organs is known as female genital schistosomiasis (FGS) and male genital schistosomiasis (MGS) respectively. Manifestations of FGS include: yellow sandy patches, mucosal bleeding and abnormal blood vessels, ulcers on the cervix and vagina, menstrual disorders, ectopic pregnancies, miscarriages, painful sexual intercourse, primary or secondary infertility ${ }^{9-13}$.

In MGS, seminal vesicles and the prostate are common sites for S.haematobium oviposition ${ }^{5,8,14}$. Manifestations include funiculitis, prostatitis, epididymitis, orchitis and urethritis among others ${ }^{15}$. Calcification of the prostate and seminal vesicles attributable to schistosomiasis can be detected by sonograpghy ${ }^{16}$. The lesions associated with schistosomiasis in men may affect spermatogenesis and consequently result in infertility ${ }^{15}$.

We reviewed patients' records at the University Teaching Hospital histopathology laboratory for the period 2001 to 2007 in order to determine and document the presence of genital schistosomiasis from biopsy specimens.

\section{METHODS}

The University Teaching Hospital (UTH) in Lusaka is Zambia's largest reference hospital and serves as the teaching hospital of the University of Zambia medical school and other health training institutions. The histopathology laboratory provides diagnostic pathological services for majority of the people in the country. The department receives histological specimens from 72 districts of Zambia and processes over 6000 specimens each year.

Histological reports for the period 2001-2007 indicating the presence of schistosomiasis were retrieved and reviewed. Provisional diagnosis as provided by the attending physician, biopsy sites and age of the patient were noted. Data were analysed by age, sex and biopsy site.

\section{RESULTS}

During the period under review, 58 case reports of schistosomiasis detected in biopsies were retrieved. Thirty eight $(65.5 \%)$ of the specimens with schistosomiasis were from the genital organs. Thirty-two $(84.2 \%)$ of all the cases with schistosomiasis were female patients while 6 $(15.8 \%)$ constituted male patients. The age range for infected patients was 4 to 74 years and the median age was 32 years.

\section{Frequency of schistosomiasis in various tissue specimens}

The distribution of schistosomiasis in various sites is shown in Table 1. Schistosomiasis was detected in tissues from 8 sites: bladder, upper female genital tract, lower female genital tract, male genital tract, intestines, liver, nose and omentum. Female genital tract schistosomiasis was more prevalent $(32 / 58$; $55.1 \%)$ than male genital schistosomiasis $(6 / 58$; $10.3 \% ; \mathrm{p}<0.001)$. Schistosomiasis of the lower female genital tract was higher $(26 ; 44.8 \%)$ than the upper female and the male genital tracts (10.3 $\%)$.This difference was statistically significant $(\mathrm{p}<0.001)$.

Table 1: Distribution of Schistosomiasis in specimens collected from different sites

\begin{tabular}{ll}
\hline Incision site involved & $\begin{array}{l}\text { Number of Patients } \\
\text { n (\%) }\end{array}$ \\
\hline Lower female genital tract & $26(44.8)$ \\
Upper female genital tract & $6(10.3)$ \\
Male genital tract & $6(10.3)$ \\
Intestine & $10(17.2)$ \\
Urinary Bladder & $6(10.3)$ \\
Liver & $2(3.5)$ \\
Omentum & $1(1.7)$ \\
Nose & $1(1.7)$ \\
\hline
\end{tabular}

\section{Schistosoma infection in the genital sites}

Schistosoma infection in various organ sites is shown in Table 2. Schistosoma infections were high in genital specimens collected from the cervix $(34.2 \%)$, followed by those from the vulva $(13.2 \%)$. In male patients, the distribution of the infection was 
the same in the prostate, spermatic cord and testicular tissues $(5.3 \%)$. Double site infection was detected in one patient involving the uterus and the ovary, while in another, the ovary and the fallopian tubes were affected. In the third patient, the uterus, ovary and the cervix were affected. Clinical findings in some of the patients where data were available included cervical polyps, contact bleeding, genital warts, and ulcerated skin. In one patient, a miscarriage was reported.

Table 2: Distribution of schistosomiasis in specimens from the genital sites

\begin{tabular}{|lll|}
\hline Biopsy site involved & $\begin{array}{l}\text { No. Patient } \\
\text { Detected }\end{array}$ & Percentage \\
\hline Cervix & 13 & \\
Vulva & 5 & 34.2 \\
Perineum & 3 & 13.1 \\
Ovary & 2 & 7.9 \\
Vagina & 2 & 5.3 \\
Peritoneum & 2 & 5.3 \\
Prostate & 2 & 5.3 \\
Spermatic cord & 2 & 5.3 \\
Testicles* & 2 & 5.3 \\
Ovary and fallopian tube & 1 & 5.3 \\
Uterus & 1 & 2.6 \\
Uterus and ovary & 1 & 2.6 \\
Uterus, ovary and cervix & 1 & 2.6 \\
Labium (Left) & 1 & 2.6 \\
Total & 38 & 2.6 \\
& & 100 \\
\hline
\end{tabular}

*Testicular schistosomiasis in 13 year old boy.

\section{Genital schistosomiasis in the different age groups}

Uterine cervical schistosomiasis was the highest form of female genital schistosomiasis $(53 \%)$ in the $30-42$ years age group, followed by $17-29$ years age group $(25 \%)$. In younger girls less than 16 years, the vulva was the most affected part (Table3). Genital wart was the presenting complaint in all the girls with vulva schistosomiasis. Vulva schistosomiasis was also noted in a 32 year old female who had presented at the hospital with itching on the affected part.

In male genital schistosomiasis, three of the six patients were under the age of 20 years (13 years, 14 years and 16 years), while the others were aged 41 , 56 and 70 years. In the 16 -year-old male, both the left and right spermatic cords were infected with numerous schistosoma ova. Multiple schistosoma granulomas were detected in the testicular tissue from a 13-year-old male patient.
Table 3: Schistosoma infection in female genital organs according to age groups

\begin{tabular}{lcccc}
\hline Organ involved & \multicolumn{5}{c}{ Age Group in years } \\
& $4-16$ & $17-29$ & $30-42$ & $>43$ \\
\hline Cervix & a & 2 & 10 & 1 \\
Ovary & - & 2 & - & - \\
Ovary and fallopian tube & 1 & - & - & - \\
Uterus & - & - & 1 & - \\
Uterus and ovary & - & - & 1 & - \\
Uterus, ovary and cervix & - & - & - & 1 \\
Vagina & - & 2 & - & - \\
Vulva & 3 & 1 & 1 & - \\
Labium (left) & 1 & - & - & - \\
Perineum & - & - & 3 & - \\
Peritoneum & - & 1 & 1 & \\
\hline Total & $\mathbf{5 ( 1 5 . 6 )}$ & $\mathbf{8 ( 2 5 \% )}$ & $\mathbf{1 7 ( 5 3 \% )}$ & $\mathbf{2 ( 6 . 3 \% )}$ \\
\hline
\end{tabular}

Schistosoma infection and malignancy

In $28(74 \%)$ of the genital schistosomiasis cases, malignancy was clinically suspected but histologically only 3 cases of malignancy were detected alongside the schistosoma infections. Two of these were detected in cervical tissues while 1 case was diagnosed from prostate tissue. Histological examination of the specimen from the 70 -year-old male patient revealed schistosomiasis and cancer of the prostate.

\section{DISCUSSION}

Results from our retrospective study show that genital schistosomiasis is prevalent in Zambia although there were no clinical suspicions of Schistosomiasis in any of the cases. The clinical diagnosis in most of these patients was malignancy. Genital schistosomiasis is normally not suspected in most of the cases and is usually detected accidentally during the course of other examinations $^{7,13,17}$ or from post-mortem and histopathological studies ${ }^{18}$.

In this review, schistosomiasis of the lower genital tract was more common than upper genital tract, with the uterine cervix being the most affected. Similar findings have been reported in Malawi and Tanzania ${ }^{19,20}$. Among the 58 cases of schistosomiasis detected, the majority $(65.5 \%)$ were identified from genital specimens suggesting that the infection was due to $S$. haematobium although 
the records did not specify. However in Tanzania, the occurrence of genital schistosomiasis was the same in genital and urinary organs ${ }^{21}$. Attili et al. also reported the presence of genital schistosomiasis from histological tissues collected from women with suspected sexually transmitted diseases at a specialized clinic in Lusaka, Zambia ${ }^{7}$. Though the infection was reported in the early 1980s, it still remains unrecognized.

With the infection being more predominant in the lower genitals, the cervix appears to be the preferred site $^{4}$ probably by $S$. haematobium. Poggensee et al. ascribed the occurrence of the infection in the female genital organs to variation in the vascular tissues during puberty and a shift in the direction of flow of blood when one is pregnant ${ }^{18}$. We found the prevalence of genital schistosomiasis to be higher in tissues from the cervix compared to tissues from other parts of the genital tract. Multiple site infection was also noted in one patient in our review in which the cervix, ovary and the uterus were affected. Similar finding as above have been documented elsewhere ${ }^{21}$. Chronic cervical schistosomiasis can lead to erosion of the cervical epithelium rendering it susceptible to infections such as Human Immunodeficiency Virus (HIV) and Human Papilloma Virus (HPV). As HIV infection is highly prevalent in Sub-Saharan Africa ${ }^{22}$, the risk of acquiring and transmitting HIV in these women is increased ${ }^{9}$. It would be hypothesized therefore, that the prevalence of HIV infections in women living in schistosoma endemic areas in Zambia may be higher than in non-endemic areas.

Schistosomiasis of the vulva is usually common in patients without prior exposure to the infection such as women from non endemic countries and children below the age of 15 years. However, presentations such as ulceration, masses and vulva swelling are seen more in patients with chronic infections ${ }^{23}$. Vulval schistosomiasis was detected more in biopsies from girls less than 15 years of age in our study. Four of these children had presented with lesions clinically identified as warts. Similar findings were reported in case studies among travellers who had visited endemic areas ${ }^{23,24}$.

Although MGS has been reported more in older male patients ${ }^{14}$, younger males can equally be infected as was observed in our study where 2 of the
6 male patients were below the age of 15 years. Probable consequences of genital schistosomiasis on reproductive health have been documented ${ }^{21}$ and can be devastating psychologically. It is on this background that the World Health Organisation recommends that treatment be given early in life to prevent adverse chronic manifestations later in adulthood.

Chronic infections with $S$. haematobium can lead to bladder cancer. However, its association with cervical cancer is still debatable ${ }^{21}$. In this study, histologic examination of cervical biopsies from two women with cervical schistosomiasis demonstrated the presence of squamous cell carcinoma. In Zambia, cancer of the cervix accounts for $30.6 \%$ of all the cancers detected ${ }^{25}$. It is not known whether any of the cancer cases were linked to schistosomiasis or were due to other inherent biological factors.

Based on this review, we recommend that community-based studies be conducted to describe the true magnitude of the disease in both women and men living in endemic areas. As misdiagnosis can lead to improper management of the patients, genital schistosomiasis should also be considered as one of the differential diagnoses in sexually transmitted diseases and cervical cancer, especially in patients from Schistosoma-endemic areas. Deliberate programs for health workers and outreach programs for the communities must be formulated and implemented in order to raise awareness on genital schistosomiasis.

\section{CONCLUSION}

In conclusion, this study shows that genital schistosomiasis is prevalent in Zambia and affects mainly females. Uterine cervical schistosomiasis was the most prevalent of all forms of female genital schistosomiasis and mostly affected middle-aged women in the 30-42-year age-group.

\section{ACKNOWLEDGEMENTS}

The authors wish to thank histopathology staff, particularly, Mr. Eric Mulenga and Mrs. Ndolesha Chimbelu for helping in retrieving the records. We also thank the Department of Pathology and Microbiology, University Teaching Hospital for allowing us to analyse and publish this data. 


\section{REFERENCES}

1. Touré S, Zhang Y, Bosqué-Oliva E, Ky C,Ouedraogo A, Koukounari A, Gabrielli AF, Sellin B, Webster JP, Fenwick A. Two-year impact of single praziquantel treatment on infection in the national control programme on schistosomiasis in Burkina Faso. Bulletin of the World Health Organization 2008; 86.

2. Zambia Bilharzia control program. Knowledge, Attitudes and Practice (KAP) survey of soil transmitted helminthes and schistosomiasis.2007, MOH publication.

3. Gryseels B, Polman K, Clerinx, Kestens L. Human Schistosomiasis. The Lancet. 2006; 368:10391126.

4. Poggensee G, Sahebali S, Van Marck E, Swai B, Krantz I, Feldmeier H. Diagnosis of genital cervical schistosomiasis: Comparison of Cytological, Histopathological and Parasitological examination. Am J Trop Med Hyg. 2001; 65 (3):233-236.

5. Feldmeier H, Leutscher P, Poggensee G, Harms G. Male genital schistosomiasis and haemospermia. Trop Med Int Health. 1999; 4(12):791-793.

6. Leutscher P, Ravaoalimalala VE, Raharisolo C, Ramarokoto C E, Vennervald B, Esterre P, Feldmeier H. Clinical findings in female genital schistosomiasis in Madagascar. Trop Med Int Health. 1998; 3(4):327-332.

7. Attili VR, Hira SK, Dube M K. Schistosomal genital granulomas: a report of 10 cases. Br J.Vener Dis.1983; 59:269-272.

8. Leutscher P, Ramarokoto C, Reimert C, Feldmeier H, Esterre P, Vennervald BJ. Community based survey of male schistosomiasis in Madagascar. The Lancet. 2000; 355 (9198):118.

9. Kjetland EF, Ndhlovu PD, Mduluza T, Gomo E, Gwanzura L ,Mason PR ,Kurewa NE, Midzi N, Friis H, Gundersen SG. Simple clinical manifestations of genital Schistosoma haematobium infection rural Zimbabwean women. Am J Trop Med Hyg. 2005; 72 (3):311-319.

10. Talaat M, Watts S, Mekheimar S, Ali HF, Hamed H.The context of Reproductive health in an Egyptian hamlet: a pilot study to identify female genital schistosomiasis. Soc Sci Med.2004; 58:515524.

11. Boers KE,Sastrowijoto PH, van Elzakker EPM,Hermans MPM. Schistosomiasis of the Uterus in a patient with dysmenorrhoea and menorrhagia.

12. Leutscher P, Ravaoalimalala VE, Raharisolo C, Ramarokoto CE, Vennervald B, Esterre P, Feldmeier H. Clinical findings in female genital schistosomiasis in Madagascar. Trop Med and Int Health. 1998; 3(4):327-332.
13. Swart PJ, Van der merwe JV. Wet smear diagnosis of genital schistosomiasis. South African Medical Journal. 1987; 72:631-632.

14. Leutscher PDC, van Dam GTJ, Reimert CM, Ramarokoto CE, Deelder AM, Ørnbjerg N. Eosinophil Cationic Protein, Schistosoma Egg Antigen, Circulating Anodic Antigen and Egg Excretion in Male Urogenital Schistosomiasis. Am JTrop Med Hyg. 2008. 79 (3):422-426.

15. Perignon A, Pelicot M, Consigny HP. Genital schistosomiasis in Travellers. J Travel Med. 2007; 14(3), 197-199.

16. Vilana R, Corachan M, Gascon J, Valls E, Bru C. Schistosomiasis of the male genital tract: Transrectal sonographic findings. J Urol. 1997; 158:1491-1493.

17. Sarma HN, Jeebun N, Agnihotri. Incidental schistosomiasis in a dermoid cyst of the ovary: A case Report. Internet J Pathol. 2008; 7 (1).

18. Poggensee G, Feldmeier H, Krantz I. Schistosomiasis of the female genital tract: Public health aspects. Parasitol Today. 1999; 15:9.

19. Kjetland EF, Poggense G, Helling- Giese. G, Richter J, Sjaastad A, Chitsulo L, Kumwenda N, Gundersen GS, Krantz I, Feldmeier H. Female genital schistosomiasis due to S. haematobium. Clinical and parasitological findings in women in rural Malawi. Acta Trop. 1996; 62:239-255.

20. Poggensee G, Kiwelu I, Weger V, Goppner D, Diedrich T, Krantz I, Feldmeier H. Female genital schistosomiasis of the lower genital tract: Prevalence and disease associated morbidity in Northern Tanzania. J Infect Dis. 2000; 181:12101213.

21. Swai B, Poggensee G, Mtweve S, Krantz I. Female genital schistosomiasis as an evidence of neglected cause for reproductive ill health: A retrospective histopathological study from Tanzania. BMC Infect Dis. 2006; 6:1-8.

22. Joint United Nations Program on HIV/AIDS (UNAIDS). Report on the global AIDS epidemic. 2008.

23. Carey FM, Quah SP, Hedderwick S, Finnegan D, Dinsmore WW, Maw RD. Genital schistosomiasis: A case Report. Int J STD AIDS. 2001; 12:609-614.

24. Goldsmith PC, Leslie TA, Sams V, Bryceson ADB ,Allason-Jones E, Dowd PM. Lesions of schistosomiasis mimicking warts on the vulva. J.R Soc Med. 1993; 86:51.

25. WHO/ICO Information centre on HPV and cervical cancer Summary Report on HPV and cervical cancer statistics in Zambia. 2007.[Accessed 17/09/2008] 